\title{
Meeting evolving technology education challenges in photonics and optics
}

\section{William Woodward}

William R Woodward, "Meeting evolving technology education challenges in photonics and optics," Proc. SPIE 8481, Optics Education and Outreach II, 848108 (15 October 2012); doi: 10.1117/12.929273

EDIE Event: SPIE Optical Engineering + Applications, 2012, San Diego, California, United States 


\title{
Meeting Evolving Technology Education Challenges in Photonics and Optics
}

\author{
William R. Woodward \\ UrsaNav Inc., 616 Innovation Drive, Chesapeake VA, 23320 \\ Electronics Technicians Association, International, 5 Depot Street, Greencastle IN, 46135
}

\begin{abstract}
The rapid evolution of technology places great challenges on educators and employers to train and certify personnel in these technologies in a timely way. A cooperative effort between international standards organizations and the Electronics Technicians Association, International (ETA) is pioneering a new approach to meet the challenges of evolving technology education in the areas of photonics and optics. ETA recently introduced two optics certifications and two photonics certifications. Each of these certifications contains multiple knowledge and hands-on examinations that were developed specifically to meet the needs of industry.
\end{abstract}

Keywords: ETA, evolving, education, certify, certification, photonics, optics, standards

\section{INTRODUCTION}

The needs of the world are highly dependent on the supply of trained personnel to install, operate, and maintain the emerging technologies. Technologies are evolving so quickly that previously defined technologies are bypassed as the industry moves to the next generation of devices. This rapid development of technology places great challenges on educators to train and certify personnel in these technologies in a timely way.

As technology rapidly evolves, the intellectual property associated with that technology typically can only be found within a small group of subject matter experts located in various parts of the world. The details of the technology do not typically find their way into the classroom until a textbook is published and the ancillary package is completed. With all the advances in publishing, this process can still take years and there is no guarantee that information available to instructors is complete.

The greatest concentration of subject matter experts can be found within the working groups of international standards organizations. The Electronics Technicians Association, International (ETA) has been working with multiple international standards organizations to create a certification infrastructure that aligns with the training standards these organizations have developed. Recently the ETA introduced two optics certifications and two photonics certifications. Each of these certifications contains multiple knowledge and hands-on examinations that were developed specifically to meet the needs of industry.

This paper provides an overview of the photonics and optics certifications currently available and the standards that are in development.

\section{ETA}

The ETA is a not-for-profit worldwide association whose mission is to represent and support the technical professional ${ }^{1}$. Founded in 1978 by electronics technicians, the ETA aligns with international standards, vocational and education

Optics Education and Outreach II, edited by G. Groot Gregory, Proc. of SPIE Vol. 8481

$848108 \cdot$ ( ) 2012 SPIE · CCC code: 0277-786/12/\$18 · doi: 10.1117/12.929273 
curriculums, and businesses' resource initiatives through certification programs, conferences, speaking engagements, and book and journal publications.

\subsection{Membership}

Members are professionals in all technical fields, including fiber optics, photonics, optics, smart-home, renewable energy, customer service, biomedical, computer and computer networking, telecommunications, wireless communications, consumer electronics, video distribution, aviation, industrial electronics, radar, and satellite. ETA members range in occupation from college professors to beginner installers and technicians to company chairpersons.

\subsection{Certification}

Recognizing the need to verify that technicians had sufficient training in industry standards, including troubleshooting techniques, knowledge of test equipment, and installation procedures, ETA began providing third-party assessment through its own certification programs in 1978. Aligning with the ISO 17024 standard and collaborating with education providers and industry professionals, ETA certifications test the knowledge and hands-on skills needed in today's electronics industry. The organization currently has stand-alone certifications and Journeyman certifications for more than 80 certification programs.

ETA tests and certifies thousands of technicians and industry specialists each year. The organization has its own Board of Directors, more than 600 subject matter experts serving on various certification advisory committees, a professional certification administration staff, training facilities, and more than 1,000 exam certification administrators. ETA actively supports training and education through the development of study guides, technical monographs and seminars, as well as working with a large number of ETA-approved schools and courses.

An ETA certification signifies that the holder has demonstrated professional proficiency and has the technical knowledge and skill to meet international industry standards. Their certification programs are non-discriminatory, objective, and reasonably priced, setting ETA apart from other manufacturer and product-related certifications.

\subsection{Affiliations}

ETA is actively involved in a wide variety of industry related organizations. Affiliations can be viewed on their website www.eta-i.org.

\section{DEVELOPING THE PHOTONICS AND OPTICS CERTIFICATIONS}

In 2009, ETA began working with James E. Pearson, PhD, Special Consultant for the University of Central Florida Center for Research and Education in Optics and Lasers (CREOL) and the Executive Director of the Florida Photonics Cluster on an Optics and Laser Technician Certification Program. One of the goals of this project was to develop certifications for Photonics Specialists, Photonics Operators, and Precision Optics Technicians. In November 2011, ETA announced the release of the new Photonics and Precision Optics certifications.

The following sections in this paper provide an overview of the knowledge and hands-on competencies for each certification. A complete copy of the competencies is available on the ETA website at www.eta-i.org.

\section{PHOTONICS TECHNICIAN OPERATOR (PTO)}

Photonics technicians work in jobs where they assemble, measure, test, and repair optical components such as lenses, mirrors, filters, and optical sources such as lasers and light-emitting diodes (LEDs) ${ }^{2}$. 


\subsection{Operator Level}

These technicians typically work in applications where photonics is an "enabling technology" such as manufacturing/materials processing, internet/communications, biomedical equipment, and defense/homeland security systems development/integration. They set up, calibrate, operate, monitor, maintain, and sometimes repair equipment containing lasers, optics, fiber optics and/or electro-optic or other photonics devices that are being used in their organization.

\subsection{Knowledge Competencies}

Certification requires competence in the following knowledge areas:

- Applied mathematics

- Principles of Optics

$\circ \quad$ Nature of light

- Geometrical optics

- Wave optics

- Basics of laser physics and devices

- Safety

The required knowledge competence can be demonstrated with a passing score of $75 \%$ or better on each of the Photonics Technician Operator Certification exam sections. These exam sections are required of all applicants, regardless of formal education, training, or work experience.

\subsection{Hands-On Competencies}

Certification requires competence in the following hands-on competency areas:

- Laser device \& systems skills

- Photonic/optical component \& system skills

- Electronics skills

- Basic technical skills

The required hands-on competence can be demonstrated with one or more of the following:

- A letter from an employer, preferably a supervisor who has been certified, certifying that the person has demonstrated the competencies listed.

- A transcript with a grade of $\mathrm{C}$ or better in the subject matter from an accredited college, university, or technical school

\section{PHOTONICS TECHNICIAN SPECIALIST (PTS)}

Photonics technicians work in jobs where they assemble, measure, test, and repair optical components such as lenses, mirrors, and filters and optical sources such as lasers and light-emitting diodes (LEDs) ${ }^{3}$.

\subsection{Specialist Level}

These technicians work in areas that require the skills and knowledge of the Operator Level, but also require a higher level of knowledge of optics and photonics. In addition, there are a greater number of hands-on competencies in laser and optical components and systems. Specialists typically work in applications such as:

- Research and development laboratory techs 
- Product development, test, and production techs who are team members for original equipment manufacturers (OEMs) of lasers, optics, and photonics components and systems

- Field service techs for OEMs or companies that manufacture and/or utilize lasers, optics, and photonics components and systems

\subsection{Knowledge Competencies}

Certification requires competence in the following knowledge areas:

- Applied mathematics

- Principles of Optics

$\circ \quad$ Nature of light

○ Geometrical optics

○ Wave optics

- Basics of laser physics and devices

- Safety

The required knowledge competence can be demonstrated with a passing score of $75 \%$ or better on each of the Photonics Technician Specialist Certification exam sections. These exam sections are required of all applicants, regardless of formal, education, training or work experience.

\subsection{Hands-On Competencies}

Certification requires competence in the following hands-on competency areas:

- Laser device \& systems skills

- Photonic/optical component \& system skills

- Electronics skills

- Basic technical skills

The required hands-on competence can be demonstrated with one or more of the following:

- A letter from an employer, preferably a supervisor who has been certified, certifying that the person has demonstrated the competencies listed.

- A transcript with a grade of $\mathrm{C}$ or better in the subject matter from an accredited college, university, or technical school

\section{TECHNICIAN IN PRECISION OPTICS (TPO)}

Precision Optics technicians work in the technical area of optical component fabrication in optical shops for optics manufacturers, and in quality control departments (incoming and/or outgoing inspection) for organizations that incorporate precision optics into various systems ${ }^{4}$. They must understand and be able to examine the properties and uses of a variety of bulk materials, have experience in the use of equipment and procedures for shaping polishing and coating precision optics, and the use of optical instruments, procedures and guidelines for verifying optical component dimensions and tolerances. They can also handle, store and ship precision optical components. 


\subsection{Technician Level}

These technicians have the minimum required hands-on competencies and experience with fabrication and testing of fewer types of optics.

\subsection{Knowledge Competencies}

Certification requires competence in the following knowledge areas:

- Applied mathematics

- Safety

The required knowledge competence can be demonstrated with a passing score of $75 \%$ or better on each of the Technician in Precision Optics Certification exam sections. These exam sections are required of all applicants, regardless of formal education, training, or work experience.

\subsection{Hands-On Competencies}

Certification requires competence in the following hands-on competency areas:

- Specific technical skills in

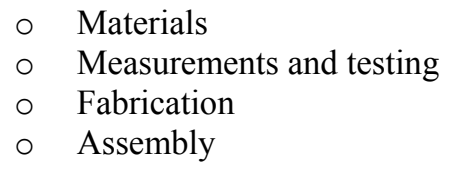

- Basic technical skills

The required hands-on competence can be demonstrated with one or more of the following:

- A letter from an employer, preferably a supervisor who has been certified, certifying that the person has demonstrated the competencies listed.

- A transcript with a grade of $\mathrm{C}$ or better in the subject matter from an accredited college, university, or technical school

\section{SPECIALIST IN PRECISION OPTICS (SPO)}

Precision Optics technicians work in the technical area of optical component fabrication in optical shops for optics manufacturers, and in quality control departments (incoming and/or outgoing inspection) for organizations that incorporate precision optics into various systems ${ }^{5}$. They must understand and be able to examine the properties and uses of a variety of bulk materials, have experience in the use of equipment and procedures for shaping, polishing, and coating precision optics, and the use of optical instruments, procedures and guidelines for verifying optical component dimensions and tolerances. They can also handle, store and ship precision optical components.

\subsection{Specialist Level}

These technicians require a greater range of hands-on competencies and experience with fabrication and testing of a wider range of types of optics and optical coatings than the TPO. 


\subsection{Knowledge Competencies}

Certification requires competence in the following knowledge areas:

- Applied mathematics

- Principles of Optics: nature of light, geometrical optics, wave optics

- Safety

The required knowledge competence can be demonstrated with a passing score of $75 \%$ or better on each of the Specialist in Precision Optics Certification exam sections. These exam sections are required of all applicants, regardless of formal education, training, or work experience.

\subsection{Hands-on Competencies}

Certification requires competence in the following hands-on competency areas:

- Specific technical skills in:

○ Materials

$\circ$ Measurements and testing

- Fabrication: component and coating

○ Assembly

- Basic technical skills

The required hands-on competence can be demonstrated with one or more of the following:

- A letter from an employer, preferably a supervisor who has been certified, certifying that the person has demonstrated the competencies listed.

- A transcript with a grade of $\mathrm{C}$ or better in the subject matter from an accredited college, university, or technical school

\section{STANDARDIZING THE CERTIFICATIONS}

For almost a decade ETA and SAE International have worked together to create aerospace fiber optic knowledge and hands-on training standards. The Aerospace industry has always required the highest standards of workmanship to be maintained. To ensure that the aerospace fiber optics industry adopted these same high standards, SAE AS-3 Fiber Optics and Applied Photonics committee created ARP5602, A Guideline for Aerospace Platform Fiber Optic Training and Awareness Education ${ }^{6}$. This document and the 10 slash sheets establish the minimum knowledge and hands-on training and certification requirements for all personnel working or associated with fiber optic components or systems in accordance with aerospace industry best practices.

In 2009, AS-3 expanded their training efforts into the area of photonics with ARP6180, A Guideline for Aerospace Platform Photonics Training and Awareness Education? ${ }^{7}$ This effort began as a result of working with the Florida Photonics Cluster and a group of subject matter experts on an Optics and Laser Technician Certification Program. One of the goals of this project was to develop certification standards for Photonics Specialists, Photonics Operators, and Precision Optics Technicians. This standard will help fill a critical_need for a reliable supply of workers skilled in aerospace photonics. 


\section{CONCLUSION}

The rapid evolution of technology places great challenges on educators and employers to train and certify personnel in these technologies in a timely way. The cooperative effort between ETA and SAE has pioneered a new approach to meet the challenges of evolving technology education in the areas of aerospace fiber optics, photonics, and optics. The standards created in this cooperative effort and maintained by AS-3, will help educators meet the challenges they are facing for decades to come.

\section{REFERENCES}

[1] ETA, About the Electronics Technicians Association, International, http://www.eta-i.org/about_eta.html

[2] ETA, Photonics Technician Operator, http://www.eta-i.org/Comps/PTO\%20Comps.pdf

[3] ETA, Photonics Technician Specialist, http://www.eta-i.org/Comps/PTS\%20Comps.pdf

[4] ETA, Technician in Precision Optics, http://www.eta-i.org/Comps/TPO\%20Comps.pdf

[5] ETA, Specialist in Precision Optics, http://www.eta-i.org/Comps/SPO\%20Comps.pdf

[6] SAE International, ARP5602, A Guideline for Aerospace Platform Fiber Optic Training and Awareness Education, http://standards.sae.org/arp5602

[7] SAE International, ARP6180, A Guideline for Aerospace Platform Photonics Training and Awareness Education, http://standards.sae.org/wip/arp6180 